\title{
Pain evaluation in a sample of Turkish children with cerebral palsy and its association with dependency level, verbal abilities, and the quality of life of patients and sociodemographic status, depression, and quality of life of their caregivers
}

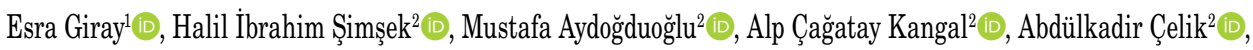 \\ Cihat Kurt² ${ }^{1 D}$, Evrim Karadağ Sayg1 $1^{1}$ (D) \\ ${ }^{1}$ Department of Physical Medicine and Rehabilitation, Marmara University School of Medicine, İstanbul, Turkey \\ ${ }^{2}$ Marmara University School of Medicine, (Student), İstanbul, Turkey
}

Received: June 11, 2017 Accepted: November 19, 2017 Published online: February 23, 2018

\begin{abstract}
Objectives: This study aims to evaluate pain in children with cerebral palsy (CP), to investigate its association with dependency level, verbal abilities, and the quality of life (QoL) of children and sociodemographic status, depression levels, and QoL of their caregivers.

Patients and methods: Between February 2016 and April 2016, a total of 85 children (56 males, 29 females; mean age $7.1 \pm 2.5$ years; range, 4 to 12 years) with CP were included. Their sociodemographic data, gross motor functional levels, verbal abilities (verbal and nonverbal) were evaluated. The children were categorized as independent (Gross Motor Function Classification System [GMFCS] 1), partially dependent (GMFCS 2,3), and totally dependent (GMFCS 4,5). The Non-Communicating Children's Pain Checklist - Revised (NCCPC-R), the Caregiver Priorities \& Child Health Index of Life with Disabilities (CPCHILD), the Nottingham Health Profile (NHP), and the Beck Depression Inventory (BDI) were used for the evaluation.

Results: A total of 50 (58.8\%) of the children were verbal, while 35 (41.2\%) were non-verbal. Of the patients, $47.1 \%$ were totally dependent, $37.6 \%$ were partially dependent, and $15.3 \%$ were independent. Pain was less frequent in the independent group, compared to the partially and totally dependent groups $(\mathrm{p}=0.04 ; \mathrm{p}=0.013)$. There were no statistically significant difference in perceived pain according to the CPCHILD and NCCPC-R scores, when low and high socioeconomic status were compared ( $>0.05)$. The QoL scores of children who were totally dependent and non-verbal were statistically significantly lower than those of the other children ( $\mathrm{p}=0.0001, \mathrm{p}=0.0001)$. A statistically significantly negative correlation between increased totally dependent children's QoL scores and decreased QoL scores of the caregivers was observed $(\mathrm{r}=-0.429 \mathrm{p}=0.006)$. The children with pain had a decreased QoL $(\mathrm{p}=0.03)$. The QoL of caregivers decreased and the depression scores of caregivers increased, as the pain scores of the children increased $(\mathrm{r}=0.291, \mathrm{p}=0.007 ; \mathrm{r}=-0.455, \mathrm{p}=0.0001)$.

Conclusion: Our study results show that pain is more frequent in children with CP who are dependent and non-verbal, and it negatively affects the QoL of both caregivers and children. Evaluation of pain and the identification of CP patients who are at high risk of experiencing pain is worthwhile, as these individuals have difficulty in verbalizing pain due to their cognitive problems, although they are at risk of experiencing pain due to chronic physical problems, such as spasticity and contracture, as well as interventions for complicated medical problems.
\end{abstract}

Keywords: Caregivers; cerebral palsy; depression; pain; quality of life.

Cerebral palsy (CP) is a group of permanent impairments of movement and posture development that result in activity restrictions caused by nonprogressive disturbances that occurred in the developing fetal or infant brain. ${ }^{[1]}$ The actual brain damage does not progress, which differentiates CP from similar conditions. The brain damage occurs in parts of the brain that affect muscle tone, gross and fine motor functions, balance, control, reflexes, and posture. These are mainly orthopedic in nature and are considered primary conditions of CP. Primary conditions which are a direct result of 
brain impairment (disturbances of motor control, muscle tone, posture and balance), in turn, may lead to secondary conditions such as inability to chew, inability to swallow, breathing difficulties, bladder and bowel control issues, and communication difficulties. ${ }^{[2]}$ Also, associated conditions including intellectual impairment, epileptic seizures, and hearing and vision impairment can occur in CP. Children with $\mathrm{CP}$ are also at risk for chronic pain originating from both primary conditions and secondary and conditions. The possible causes of pain in CP can be classified as surgical, procedural, gastrointestinal, orthopedic, neuromuscular, and rehabilitative causes, and other causes include trauma, infection, and common childhood pain. ${ }^{[3]}$ In addition, children with $\mathrm{CP}$ are at risk for pain due to both chronic physical problems such as spasticity and contractures, secondary problems and interventional treatments targeting complicated medical problems. ${ }^{[4]}$ As a result, although there are many potential contributors to pain in children with $\mathrm{CP}$, awareness of the presence of pain is low among health care providers. Pain in children with $\mathrm{CP}$ is a relatively new area of study, since it is common and difficult to recognize due to communication challenges of the children with CP. ${ }^{[5,6]}$ Moreover, clinicians focus on the medical problems associated with $\mathrm{CP}$, and their treatment, and the evaluation of pain is ignored.

Unrecognized pain may have negative implications on quality of life (QoL) and participation in daily living activities, both as a result of limited mobility resulting from pain itself and fear-driven avoidance of specific activities. Also, unmanaged and unrecognized pain may lead to increased stress on family members. ${ }^{[7]}$ Several studies have shown that psychosocial problems are present in primary caregivers, and the parents of children with $\mathrm{CP}$ have worse physical and emotional health than the parents of normal, healthy growing children. ${ }^{[8-10]}$ The functional and psychosocial problems experienced by children with CP can negatively affect the QoL of both the child and the caregiver, and pain in these children also has important consequences in this respect. ${ }^{[10,11]}$ Therefore, it is of utmost importance to evaluate pain and to identify $\mathrm{CP}$ patients who are at risk of pain.

In the present study, we aimed to evaluate pain in a random sample of Turkish children with $\mathrm{CP}$ and to investigate its association with dependency level, verbal abilities, the QoL of children and sociodemographic status, depression, and QoL of the caregivers.

\section{PATIENTS AND METHODS}

A total of 85 children (56 males, 29 females; mean age $7.1 \pm 2.5$ years; range, 4 to 12 years) with $\mathrm{CP}$ at the Physical Medicine and Rehabilitation outpatient clinics of Pediatric Rehabilitation of Marmara University School of Medicine between February 2016 and April 2016 were included. Exclusion criteria were the inability of the family to participate in the study, previous interventional procedures, such as surgery within the last one week, and using painkillers. The sociodemographic characteristics of patients with CP and their families were evaluated, and the gross motor functional levels of the children were assessed, according to the Gross Motor Function Classification System (GMFCS). The children were grouped into verbal and non-verbal according to their ability to speak and express the presence of pain, the severity and frequency of pain, and to point out the painful region. The Caregiver Priorities \& Child Health Index of Life with Disabilities (CPCHILD), Noncommunicating Children's Pain Checklist - Revised (NCCPC-R), Nottingham Health Profile (NHP), the Beck Depression Inventory (BDI) were used for the evaluation. A verbal and written informed consent was obtained from the caregivers. The study protocol was approved by the University Research Ethics Committee (No: 09.2016.187/70737436-0.50.06.04). The study was conducted in accordance with the principles of the Declaration of Helsinki.

\section{Evaluation Scales}

\section{Socioeconomic level score}

Socioeconomic level scoring was used to assess socioeconomic level (Appendix 1). ${ }^{[12]}$ Income level, parents' education level, parents' occupations, housing status, number of rooms, floor of the house, heating type, consanguineous marriage, number of children, and total population of the house were assessed by assigning scores of between 1 and 4 . The mean socioeconomic level score was calculated and, then, caregivers were grouped into low and high socioeconomic status (above or below the mean score).

\section{Gross motor function classification system}

The GMFCS was developed for children with CP and contains five levels. These levels are determined according to gross movements, such as self-initiating movements by themselves, sitting, and walking with CP below the age of 12 years. As children's motor functions change with age, functions are defined according to age groups, as follows: below age 2 years, 2-4 years, 4-6 years, 6-12 years, and above the age of 


\begin{tabular}{|c|c|c|c|c|}
\hline \multicolumn{5}{|c|}{ Appendix 1. Socioeconomic level score } \\
\hline & 1 point & 2 points & 3 points & 4 points \\
\hline Income rate & Minimum wage & Minimum wage-2000 TL & $>2000 \mathrm{TL}$ & \\
\hline Mothers' education level & No education & Primary school & High school & University \\
\hline Fathers' education level & No education & Primary school & High school & University \\
\hline Fathers' job & Unemployed & Worker/officer & Self-employment & $\begin{array}{l}\text { Managerial \& admin \& } \\
\text { professionals }\end{array}$ \\
\hline Mothers' job & Housewife & Worker/officer & Self-employment & $\begin{array}{c}\text { Managerial \& admin \& } \\
\text { professionals }\end{array}$ \\
\hline Housing situation & Slum & Rent & Houseowner & \\
\hline Number of rooms & 1 & 2 & 3 & 4 or over 4 \\
\hline Fold & Basement & Entry & Upper floors & \\
\hline Heating condition & None & Stove & Heater & \\
\hline Kinship between parents & First degree & Second degree & Distant & \\
\hline Number of kids & $>5$ & $3-4$ & 2 & \\
\hline $\begin{array}{l}\text { Number of people living } \\
\text { in home }\end{array}$ & $>8$ & $5-7$ & 4 & \\
\hline Total score & & & & \\
\hline
\end{tabular}

12 years. Level differences were determined on the basis of functional limitations, hand-held mobility aids (i.e., walker, crutches, or canes), or the need for wheeled mobility vehicles and the quality of movement.

The aim of this classification system is to obtain information regarding children's gross motor function, and it is not used for the assessment of personal function or potential for progress.

Each level is summarized as follows:

Level 1: Able to walk independently. There is a limitation on gross motor skills.

Level 2: Able to walk without any assistant device. There is a limitation while walking outside.

Level 3: Able to walk with an assistant device. There is a limitation while walking outside.

Level 4: There is a limitation of movements. They can move by themselves, but need a wheelchair or someone to carry them outside.

Level 5: There is severe limitation of movement even with the use of assistant devices. ${ }^{[9]}$

\section{Non-communicating children's pain checklist-revised}

This checklist is applicable to the GMFCS Levels 1-5. ${ }^{[7]}$ This questionnaire was designed to assess the pain level and types of reaction to pain in children with CP. It contains 30 items, including questions covering vocal ${ }^{[5]}$ social, ${ }^{[5]}$ facial,,${ }^{[6]}$ activity, ${ }^{[3]}$ and body/ extremities $^{[13]}$ items. Assessment is carried out by identifying the children's behaviors in the previous 2 hours by giving actions a frequency score $(0=$ rarely, $1=$ occasionally, $2=$ usually, and $3=$ quite often). If an item does not apply to the child (e.g. cannot eat solid food or cannot reach with his/her hands) then "not applicable" is noted against that item. The NCCPC-R has been validated for use in children aged between 3 and 18 years.

The NCCPC-R was designed to ask questions to parents and caregivers and does not require any education. It can also be administered to anyone who does not know the child very well. If the total score is 7 or above, then the child is considered to have pain. A score of 6 or below indicates that the child has no pain. ${ }^{[14]}$ The NCCPC-R has high validity and reliability (Cronbach's alpha $[\alpha]=0.79$ ) for the evaluation of pain in children who have cognitive abnormalities (84\% sensitivity and $77 \%$ specificity). ${ }^{[15,16]}$

\section{Caregiver priorities \& child health index of life With disabilities}

The CPCHILD is used to assess a child's QoL using such areas of daily living activities and personal care ${ }^{[10]}$ positioning, transfer and mobility, ${ }^{[10]}$ comfort and emotions, ${ }^{[10]}$ and communication and social interaction. ${ }^{[8]}$ This index contains 72 items. The comfort and emotions subdivision assesses how often the child has experienced pain or discomfort over the 
Table 1. Pain prevalence rates according to the level of dependency and the presence of depression in mothers of children with cerebral palsy

\begin{tabular}{|c|c|c|c|c|c|}
\hline & \multicolumn{4}{|c|}{ Number of children (\%) } & \multirow[b]{3}{*}{$p$} \\
\hline & \multicolumn{2}{|c|}{$\begin{array}{l}\text { Without pain } \\
\text { (NCCPC-R <7) }\end{array}$} & \multicolumn{2}{|c|}{$\begin{array}{c}\text { With pain } \\
\text { (NCCPC-R } \geq 7)\end{array}$} & \\
\hline & $\mathrm{n}$ & $\%$ & $\mathrm{n}$ & $\%$ & \\
\hline Independent (GMFCS 1) & 13 & 100 & 0 & 0 & 0.04 (Independent-partial dependent) ${ }^{*}$ \\
\hline Partial dependent (GMFCS 2,3) & 24 & 75 & 8 & 25 & 0.013 (Independent-dependent) ${ }^{*}$ \\
\hline Totally dependent (GMFCS 4,5) & 26 & 65 & 14 & 35 & 0.36 (partial dependent-dependent) ${ }^{*}$ \\
\hline Has depression (BDI $\geq 13)$ & 59 & 77.6 & 17 & 22.4 & 0.032 \\
\hline No depression $(\mathrm{BDI}<13)$ & 4 & 44.4 & 5 & 55.6 & \\
\hline
\end{tabular}

NCCPC-R: The Non-Communicating Children's Pain Checklist-Revised; GMFCS: Gross Motor Function Classification System; BDI: Beck Depression Inventory; ${ }^{*}$ value by post-hoc pairwise comparisons.

last two weeks, with questions such as "How difficult was it for your child to eat during the past two weeks?" These questions are answered using an ordinal scale, as follows: impossible (0), very difficult (1), difficult (2), slightly difficult (3), easy (4), very easy (5), and no problem (6). In addition, the help needed to perform each activity is assessed using a 6-point ordinal scale from 0 (independent) to 7 (fully dependent). Raw item scores were transformed to a scale from 0 (worst) to 100 (best) by dividing the raw item score by the maximum possible item score and multiplying by 100. Standardized scores were generated on a scale of 0 (worst) to 100 (best) in keeping with convention of other measures of HRQL, and were calculated for each of the domains (by taking the arithmetic mean of all items within the corresponding section), as well as for the total (mean of all 36 items in the questionnaire). Missing values were handled by removing the missing items from the calculation, provided that no more than half of the items from any domain were incomplete. ${ }^{[17]}$ The CPCHILD can be calculated practically using the excel calculation program, ${ }^{[18]}$ and it has been found that the validity and reliability of CP are high. ${ }^{[14]}$

In the present study, we evaluated pain using the NCCPC- $R$ results ( $\geq 7$ painful and $<7$ painless) and the CPCHILD comfort and emotions subscale scores.

\section{Nottingham health profile}

The NHP consists of six subsections that assess emotional, social, and physical health problems, as perceived by the patient. This questionnaire consists of a total of 38 questions, including some that assess energy level, ${ }^{[4]}$ pain, ${ }^{[9]}$ physical activity, ${ }^{[9]}$ sleep, ${ }^{[6]}$ emotional reactions, ${ }^{[10]}$ and social isolation, ${ }^{[6]}$ and are answered Yes/No. The number of questions answered "Yes" in each subgroup is divided by the total number of questions in the same subgroup and the result

Table 2. Comparison of Caregiver Priorities \& Child Health Index of Life with Disabilities comfort and emotion scores between verbal and non-verbal, dependent, independent and partially dependent children and different types of cerebral palsy

$\begin{array}{lcccc}\hline & \multicolumn{3}{c}{\text { CPCHILD comfort and emotion subtest scores }} & \\$\cline { 2 - 3 } & \text {$\left.Mean } \pm \text { SD } & \text { Median } & \text { Min-Max } & p \\ \hline \text { Verbal } & 48.8 \pm 33.7 & & & <0.001 \\ \text { Non-verbal } & 16.6 \pm 18.1^{*} & & & \\ \text { Independent (GMFCS 1) } & & 97.2 & 72.2-100 & \multirow{2}{*}{0.001} \\ \text { Partial dependent (GMFCS 2,3) } & & 93.05 & 36.9-100 \\ \text { Totally dependent (GMFCS 4,5) } & & 81.9 & 19.4-100^{*}\end{array}\right\}$

SD: Standard deviation; Min: Minimum; Max: Maximum; Normally distributed data are expressed as mean \pm SD while non-normally distributed data are expressed as median (min-max). CPCHILD: Caregiver Priorities \& Child Health Index of Life with Disabilities; GMFCS: Gross Motor Function Classification System. ${ }^{*}$ Statistically significiantly different group ( $\mathrm{p}$ values by post hoc comparisons using Mann-Whitney U test: $\mathrm{p}=0.07$ (independent-partial dependent), $\mathrm{p}=0.0001$ (independent-dependent), $\mathrm{p}=0.001$ (partial dependent-dependent), ${ }^{*}$ Statistically significantly different group ( $p$ values by post hoc comparisons using Mann-Whitney $U$ test: $p=0.95$ (hemiplegic-diplegic), $p=0.0001$ (hemiplegic-tetraplegic), $p=0.001$ (diplegic-tetraplegic). 
is multiplied by 100 . Each subgroup has a value of between 0 and 100, with 100 points being considered the best general QoL for the calculated subgroup and 0 points being considered as the worst QoL for the same subgroup. ${ }^{[19]}$ The adaptation of the psychometric properties of the NHP to Turkish were studied by Kucukdeveci et al. in 2000. ${ }^{[20]}$

\section{Beck depression inventory}

The BDI measures the somatic, emotional, and cognitive symptoms found in depression. It is a selfassessment scale that includes 21 symptom categories, and the highest score that can be obtained is 63 . The higher the score is, the greater the severity of the depression is present. Scores of the BDI can vary from 0 to 63 and are often classified as follows: 0-13 no depression, 14-19 mild depression, 20-28 moderate depression, and 29-63 severe depression. This scale was developed by Beck, and it has been validated in Turkish. ${ }^{[21-23]}$

\section{Statistical analysis}

Statistical analyses were performed using the IBM SPSS version 20.0 software (IBM Corp., Armonk, NY, USA). The normal distribution of the data was analyzed using visual (histogram) and analytical methods (Kolmogorov-Smirnov/Shapiro Wilk tests). Descriptive statistics were expressed in mean, standard deviation (SD), and median (min-max) values. The frequency of pain and painlessness was evaluated using cross tables, according to the level of dependence and the presence of depression. The chi-square tests or Fisher tests (where the values of the cells were unable to provide Chi-square test assumptions) were used to determine whether there was a difference in frequency between the groups. For the post-hoc comparisons, the Bonferroni-corrected Mann-Whitney U tests were used. For the comparison of two independent groups, a t-test was used when the distribution was normal, and a Mann-Whitney $\mathrm{U}$ test was used if the distribution was not normal. The Kruskal-Wallis tests were used, when the three independent groups were compared, whereas if the distribution was normal, one-way analysis of variance (ANOVA) was used. The Mann-Whitney $U$ test was performed to test the significance of pairwise differences using the Bonferroni correction to adjust for multiple comparisons. The $\mathrm{p}$ value was adjusted $(0.05 / 3=0.017)$ to correct for multiple comparisons. With regard to correlation coefficients and statistical significance, the Pearson's correlation coefficient was calculated when both variables were of normal distribution, and Spearman's correlation analysis was used, when at least one variable was not normally distributed. A $p$ value of $<0.05$ was considered statistically significant.

A logistic regression analysis was conducted to predict presence of pain using age, sex, dependency level, type of $\mathrm{CP}$, verbal/non-verbal, presence of depression (has depression/no depression), high/low socioeconomic level, and CPCHILD total score as predictors. The univariate analyses to identify variables associated with presence of pain (with pain/ without pain) was investigated using the Chi-square, Fisher's exact, Student's t, and Mann-Whitney U tests, where appropriate. For the multivariate analysis, the variables associated with pain on univariate analyses were further included in the logistic regression analysis to determine independent predictors. A 5\% type 1 error level was used to infer statistical significance.

\section{RESULTS}

Of the patients, 23 (27.1\%) were hemiplegic, 24 (28.2\%) were diplegic, and 38 (44.7\%) were tetraplegic, (2 mixed [2.4\%, 1 dyskinetic $1.2 \%])$. A total of $50(58.8 \%)$ of the children were verbal and 35 (41.2\%) were non-verbal. The patients were grouped according to the GMFCS level, as fully dependent (GMFCS 4 and 5), partially dependent (GMFCS 2 and 3), and independent (GMFCS 1). Of the children, 13 (15.3\%) were independent, 32 (37.6\%) were partially dependent, and 40 (47.1\%) were fully dependent.

Table 3. Comparison of Caregiver Priorities \& Child Health Index of Life with Disabilities, caregivers' Nottingham Health Profile scores and socioeconomic level scores of children with and without pain

\begin{tabular}{|c|c|c|c|c|c|c|c|}
\hline & \multicolumn{3}{|c|}{$\begin{array}{l}\text { Children without pain } \\
(\text { NCCPC-R <7) }(n=63)\end{array}$} & \multicolumn{3}{|c|}{$\begin{array}{l}\text { Children with pain } \\
(\mathrm{NCCPC}-\mathrm{R} \geq 7)(\mathrm{n}=22)\end{array}$} & \multirow[b]{2}{*}{$p$} \\
\hline & Mean \pm SD & Median & Min-Max & Mean \pm SD & Median & Min-Max & \\
\hline CPCHILD & $59.7 \pm 19.0$ & & & $49.3 \pm 16.6$ & & & 0.03 \\
\hline Nottingham Health Profile & $38.5 \pm 19.9$ & & & $40.5 \pm 22.0$ & & & 0.69 \\
\hline Socioeconomic level score & & 31 & $21-39$ & & 31 & $28-40$ & 0.964 \\
\hline
\end{tabular}

SD: Standard deviation; Min: Minimum; Max: Maximum; Normally distributed data are expressed as mean \pm SD while non-normally distributed data are expressed as median (min-max); CPCHILD: Caregiver Priorities \& Child Health Index of Life with Disabilities, NCCPC-R, The Non-Communicating Children's Pain Checklist-Revised. 
Table 4. The relationship between quality of life and pain scores of children with cerebral palsy and quality of life and Beck Depression Inventory scores of caregivers

\begin{tabular}{|c|c|c|c|c|}
\hline & \multicolumn{2}{|c|}{ NHP } & \multicolumn{2}{|c|}{ BDI } \\
\hline & $\mathrm{r}$ & $p$ & $\mathrm{r}$ & $p$ \\
\hline CPCHILD total score of dependent children (GMFCS 4,5) & -0.429 & $0.006^{*}$ & -0.178 & 0.134 \\
\hline CPCHILD comfort and emotion sub test scores & -0.455 & $<0.001^{\star}$ & -0.291 & $0.007^{\star}$ \\
\hline
\end{tabular}

NHP: Nottingham Health Profile; BDI: Beck's Depression Inventory; CPCHILD: Caregiver Priorities \& Child Health Index of Life with Disabilities; GMFCS: Gross Motor Function Classification System; ${ }^{*} \mathrm{p}<0.005$.

Table 5. Logistic regression analysis of risk factors for presence of pain

\begin{tabular}{lccc}
\hline & $\mathrm{B}$ & Odds ratio $(95 \% \mathrm{CI})$ & Significance level (p) \\
\hline Age & -0.066 & $0.936(0.759-1.156)$ & 0.54 \\
Gender & -0.467 & $0.627(0.214-1.836)$ & 0.394 \\
Verbal ability (verbal, non-verbal) & -0.821 & $0.440(0.102-1.891)$ & 0.270 \\
CPCHILD total score & -0.042 & $1.04(1.002-1-086)$ & 0.03 \\
Presence of depression & 1.346 & $3.842(0.798-18.49)$ & 0.09 \\
Socioeconomic score & 0.069 & $1.072(0.906-1.267)$ & 0.419 \\
Constant & 0.048 & 1.049 & \\
\hline
\end{tabular}

CI: Confidence interval.

The patients were grouped as NCCPC-R $\geq 7$ with pain and $<7$ without pain. When all three groups were compared, it was found that independent children with $\mathrm{CP}$ had less pain than those who were fully dependent and partially dependent $(\mathrm{p}=0.04 ; \mathrm{p}=0.013)$ (Table 1$)$.

According to the CPCHILD comfort and emotion subscale scores, pain was more common in the nonverbal than in the verbal children, and more in fully dependent than in partially dependent and independent children $(p=0.001, p=0.001)$ (Table 2). In the tetraplegic CP subtype, the CPCHILD comfort and emotion subscale scores were statistically significantly lower than in the hemiplegic and diplegic subtypes $(p<0.001)$. The socioeconomic level scores revealed no difference between the children whose parents scored below average and the children whose parents scored above average in terms of whether or not they had pain, according to the CPCPILD pain and NCCPC-R $(\mathrm{p}=0.420, \mathrm{p}=0.946)$.

The total CPCHILD scores of children with pain were statistically significantly lower than those of children without pain. There was no statistically significant difference between the NHP scores of caregivers of children with and without pain (Table 3 ). In addition, depressive symptoms was more frequent in caregivers of children with $\mathrm{CP}$ who had pain $(\mathrm{p}=0.03)$ (Table 1$)$.

A statistically significant negative correlation was found between the CPCHILD scores of the dependent children and NHP scores of their mothers. As the children's pain scores increased, their QoL decreased, and depressive symptoms increased in the mothers (Table 4).

The CPCHILD total scores were also statistically significantly lower in fully dependent children than in those who were dependent and partially dependent $(\mathrm{p}<0.001)$, and in non-verbal than in verbal children $(\mathrm{p}<0.001)$ (Table 2).

The initial univariate analyses revealed that the presence of depression and CPCHILD total scores were associated with the presence of pain $(p=0.032$, $\mathrm{p}=0.026$ ). The multivariate regression analysis results further demonstrated that only CPCHILD total score was significantly associated with pain $(\mathrm{p}=0.03)$ (Table 5).

\section{DISCUSSION}

This study evaluated pain in children with $\mathrm{CP}$ in a sample of Turkish children and its association with dependency level, verbal abilities and the QoL of children and sociodemographic status, depression and QoL of the caregivers. Pain was more common in dependent children than in those who were independent and partial dependent. In a similar manner, a study conducted by Penner ${ }^{[24]}$ showed that patients with CP had an increase in their pain as their GMFCS levels increased. Another study found that the incidence and severity of pain in patients at GMFCS level 5 were higher than in patients at other GMFCS levels. ${ }^{[25]}$ However, a study involving only non-verbal $\mathrm{CP}$ children found that, unlike in our study, showed 
no relationship between the GMFCS level and the incidence and severity of pain. ${ }^{[6]}$ The authors explained that this result was due to the fact that the pain was relatively less reported by the families, as all children in the study were non-verbal.

In the literature, pain was reported more commonly in non-verbal children compared to verbal children and in the tetraplegic CP subtype, compared to other subtypes. In non-verbal children, the prevalence of pain was high (65\%), and severe pain was reported to be more common in the tetraplegic type. ${ }^{[6]}$ This can be explained by the fact that muscle shortness, tension in tendons, and widespread increased tone are more common in the spastic tetraplegic CP type.

With regard to socioeconomic status of the family, we found no differences in the perceived pain levels in children with CP. In accordance with our results, a study conducted in Malaysia showed that pain levels in children with CP did not correlate with parental psychosocial factors. ${ }^{[8]}$ These results were explained by cultural differences, different coping strategies, and unspecified financial support. In contrast with our findings, a multi-center European study showed higher pain levels in children whose parents were not working. ${ }^{[25]}$ Another study conducted in Switzerland showed a correlation between pain levels and lowincome levels, and concluded that the parents were unable to work due to their child's illness. ${ }^{[13]}$ Our contrasting results can be explained by a previous study conducted in Turkey, showing that most Turkish mothers did not work and did not report finding a caretaker to look after their child, when they needed to leave their child to go somewhere. ${ }^{[9]}$

It was shown that children who experienced more pain had a lower QoL. As a child's pain levels increased, their mother's QoL decreased and their levels of depression increased. As a dependent child's QoL increased, their mother's QoL also increased. Okumus and Pinar ${ }^{[5]}$ also showed that as children experienced more pain, their QoL and their participation in everyday activities decreased. A study conducted in Malaysia also showed similar results that pain had a negative impact on QoL and that musculoskeletal system pain resulted in the poorest QoL. ${ }^{[6]}$ In addition, it was shown that these patients attempted to limit their physical activity to avoid pain. ${ }^{[1]}$

The results of logistic regression analysis which conducted to predict the presence of pain using age, sex, dependency level; type of CP, verbal/non-verbal, presence of depression (has depression/no depression), high/low socioeconomic level, and CPCHILD total score as predictors revealed that only children's QoL contributed to the prediction of pain. Jayanath et al. ${ }^{[6]}$ found that there were no statistically significant factors associated with the frequency of reported pain, while age and tetraplegic CP type were associated with the intensity of pain.

Depression was also common in mothers with children with $\mathrm{CP}$ who experienced pain. Another study conducted in Turkey showed a negative correlation between a mother's QoL and her signs of depression. ${ }^{[10]}$ The aforementioned study suggested that mothers who had children with CP had higher BDI scores than the mothers of healthy children, but the relationship between depression and pain was not assessed in this study. Another study also conducted in Turkey showed that mothers who had a child with $\mathrm{CP}$ had a lower QoL and it was also observed that they were prone to depression. ${ }^{[8]}$ However, as in previous studies, the relationship between depression and pain was not evaluated in this study.

The limitations of the present study are its relatively small sample size and its cross-sectional nature. However, its strengths are its presentation of results that were obtained according to validated, objective methods, and its being the first investigation in Turkey to study factors related to pain (its level, being verbal/non-verbal, socioeconomic level) in children with CP. Nonetheless, we recommend further largescale, prospective studies to evaluate the causes and frequency of pain and to investigate the effect of treatment on pain relief.

In conclusion, pain is more frequently seen in children with CP who are dependent and non-verbal, and that this pain negatively affects the QoL of both mothers and children. Pain evaluation is important, as it may be an indication of development of a contracture or an increase in the level of spasticity. When evaluating children with $\mathrm{CP}$, clinicians must keep in mind the fact that those who are dependent and non-verbal frequently experience more pain. As awareness of pain increases, its diagnosis and treatment may become possible, which can increase the QoL of children and their mothers.

\section{Declaration of conflicting interests}

The authors declared no conflicts of interest with respect to the authorship and/or publication of this article.

\section{Funding}

The authors received no financial support for the research and/or authorship of this article. 


\section{REFERENCES}

1. Rosenbaum P, Paneth N, Leviton A, Goldstein M, Bax M, Damiano D, et al. A report: the definition and classification of cerebral palsy April 2006. Dev Med Child Neurol Suppl 2007;109:8-14.

2. Herring JA. Tachdjian's Pediatric Orthopaedics E-Book: From the Texas Scottish Rite Hospital for Children. Elsevier Health Sciences; 2013.

3. McKearnan KA, Kieckhefer GM, Engel JM, Jensen MP, Labyak S. Pain in children with cerebral palsy: a review. J Neurosci Nurs 2004;36:252-9.

4. Breau LM, Burkitt C. Assessing pain in children with intellectual disabilities. Pain Res Manag 2009;14:116-20.

5. Okumuş M, Pınar B. Serebral Palside Ağrı. FTR Bil Der 2011;14:63-7.

6. Jayanath S, Ong LC, Marret MJ, Fauzi AA. Parent-reported pain in non-verbal children and adolescents with cerebral palsy.Dev Med Child Neurol 2016;58:395-401.

7. Kingsnorth S, Orava T, Provvidenza C, Adler E, Ami N, Gresley-Jones T, et al. Chronic Pain Assessment Tools for Cerebral Palsy: A Systematic Review. Pediatrics 2015;136:947-60.

8. Dilek B, Batmaz İ, Karakoç M, Sarıyıldız MA, Aydın A, Çavaş $\mathrm{H}$, et al. Assessment of depression and quality of life in mothers of children with cerebral palsy. Marmara Medical Journal 2013;26:94-8.

9. Karadag-Saygi E, Giray E, Peynirci-Cersid H, Ulutatar F, Aydin R. Assessment of family environment and needs of families who have children with cerebral palsy. Turk J Phys Med Rehab 2015;61:320-5.

10. Ones K, Yilmaz E, Cetinkaya B, Caglar N. Assessment of the quality of life of mothers of children with cerebral palsy (primary caregivers). Neurorehabil Neural Repair 2005;19:232-7.

11. Tüzün EH, Guven DK, Eker L. Pain prevalence and its impact on the quality of life in a sample of Turkish children with cerebral palsy. Disabil Rehabil 2010;32:723-8.

12. Özgöçer C. Çok düşük doğum ağırlıklı riskli pretermlerin nörogelişimsel sorunları ve nörolojik morbiditeye etki eden faktörlerin araştırılması (Uzmanlık Tezi). İstanbul: T.C. Sağlık Bakanlığı Bakırkoy Kadın ve Çocuk Hastalıkları Eğitim ve Araştırma Hastanesi; 2006.

13. Grøholt EK, Stigum H, Nordhagen R, Köhler L. Recurrent pain in children, socio-economic factors and accumulation in families. Eur J Epidemiol 2003;18:965-75.

14. Narayanan UG, Fehlings D, Weir S, Knights S, Kiran $\mathrm{S}$, Campbell K. Initial development and validation of the Caregiver Priorities and Child Health Index of Life with Disabilities (CPCHILD). Dev Med Child Neurol 2006;48:804-12.

15. Breau LM, McGrath PJ, Camfield CS, Finley GA. Psychometric properties of the non-communicating children's pain checklist-revised. Pain 2002;99:349-57.

16. Breau LM, McGrath PJ, Camfield C, Rosmus C, Finley GA. Preliminary validation of an observational pain checklist for persons with cognitive impairments and inability to communicate verbally. Dev Med Child Neurol 2000;42:609-16.

17. Gordon CM, Leonard MB, Zemel BS. 2013 Pediatric Position Development Conference: executive summary and reflections. J Clin Densitom 2014;17:219-24.

18. Montané LS, Marín OR, Rivera-Pedroza CI, Vallespín E, Del Pozo Á, Heath KE. Early severe scoliosis in a patient with atypical progressive pseudorheumatoid dysplasia (PPD): Identification of two WISP3 mutations, one previously unreported. Am J Med Genet A 2016;170:1595-9.

19. Kuru P, Akyuz G, Yagci I, Giray E. Hypovitaminosis D in widespread pain: its effect on pain perception, quality of life and nerve conduction studies. Rheumatol Int 2015;35:315-22.

20. Kücükdeveci AA, McKenna SP, Kutlay S, Gürsel Y, Whalley $\mathrm{D}$, Arasil T. The development and psychometric assessment of the Turkish version of the Nottingham Health Profile. Int J Rehabil Res 2000;23:31-8.

21. Hisli N. Beck Depresyon Envanterinin üniversite öğrencileri için geçerliği, güvenirliği. Psikoloji dergisi 1989;7:3-13.

22. Tegin B. Depresyonda bilişsel bozukluklar: Beck modeline göre bir inceleme. [Yayınlanmamış Doktora Tezi] Ankara: Hacettepe Üniversitesi Psikoloji Bölümü; 1980.

23. Tuğlu C, Türe M, Dağdeviren N, Aktürk Z. Birinci basamak için beck depresyon tarama ölçeği'nin türkçe çevriminin geçerlik ve güvenirliği. Türkiye Aile Hekimliği Dergisi 2007;9:117-22.

24. Penner M, Xie WY, Binepal N, Switzer L, Fehlings D. Characteristics of pain in children and youth with cerebral palsy. Pediatrics 2013;132:407-13.

25. Parkinson KN, Gibson L, Dickinson HO, Colver AF. Pain in children with cerebral palsy: a cross-sectional multicentre European study. Acta Paediatr 2010;99:446-51. 